ECONOMÍA: TEORÍA Y PRÁCTICA • Nueva Época, número 44, enero-junio 2016,

pp. 83-114, http://www.izt.uam.mx/economiatyp/ojs

\title{
República Popular China: aprendizaje tecnológico y retos del desarrollo exportador*
}

\section{People's Republic of China: Technological Learning and Challenges of Export Led Growth}

\author{
Miguel Ángel Rivera Ríos**
}

\section{RESUMEN}

La reforma económica en la República Popular China es analizada desde una perspectiva histórica y considerando los factores político-institucionales que la sostienen; se hace hincapié en el rol crítico jugado por la economía global a través de la transferencia de tecnología, la inversión extranjera directa y la demanda externa. Se destacan, por otro lado, los desequilibrios macroeconómicos provocados por el acelerado desarrollo exportador y agudizados por el cambio de tendencia de los procesos globales. Como conclusión, se revisan y evalúan algunos cambios clave en la estrategia económica.

Palabras clave: industrialización en China, desarrollo económico, economía global, industrialización.

\section{Clasificación JEL: O12.}

\begin{abstract}
This article discusses the economic reform of the People's Republic of China, adopting a historical perspective and considering the political and institutional factors that support it; special emphasis is placed in the dependence of export led growth on global processes, in terms of transfer of technology, investment and markets. In the second part, the focus is on macroeconomic imbalances caused by accelerated export development, exacerbated by changes in the global processes. As a conclusion some key changes in economic strategy are discussed and evaluated.
\end{abstract}

Keywords: industrialization in China, economic development, global economy, industrialization.

JEL classification: $\mathrm{O} 12$.

* Fecha de recepción: 25/04/2014. Fecha de aprobación: 08/10/2015. El autor agradece el apoyo de la doctora Rosalba Polanco por sus sugerencias para mejorar la exposición y a Galia de la Rosa por su ayuda en el manejo y procesamiento de información estadística.

** Facultad de Economía de la Universidad Nacional Autónoma de México. Correo electrónico:mriver@unam.mx. 


\section{INTRODUCCIÓN}

El ascenso económico de China en las últimas tres décadas no tiene precedente en la historia económica y está obligando a reexaminar las teorías y el análisis sobre el desarrollo y sobre la intervención estatal, en medio de importantes debates en el campo de la teoría política e institucional sobre la interpretación del proceso. Lo que ha sucedido en la República Popular China (RPC), aunque pasmoso, no es enteramente nuevo, ya que los tigres asiáticos dieron previamente un ejemplo de industrialización forzada, con supresión o limitación de libertades civiles y políticas. En esas experiencias fue crucial la atracción de inversión extranjera y el aprendizaje de la tecnología occidental y japonesa para adoptar una estrategia exportadora mercantilista.

La transformación de la RPC ratifica que para el logro de un desarrollo tardío exitoso se requiere la concurrencia de tres factores: a) cohesión políticoinstitucional desarrollista, o sea, la capacidad de tomar decisiones críticas; b) condiciones externas favorables, no en el sentido convencional, sino como derechos especiales de acceso a mercados externos, captación de inversión extranjera y transferencia de tecnología, y c) dotación moderada de recursos naturales, para evadir la economía extractiva. La exposición se divide en tres partes. La primera se refiere a la articulación de los factores político-institucionales, la segunda a la lógica y secuencia de la estrategia de industrialización acelerada, y la tercera a los desequilibrios provocados por la industrialización acelerada y dependiente de las exportaciones, en el contexto de la desaceleración del crecimiento global. No se soslaya la discusión sobre el nuevo ciclo de reformas, cuyo eje parece estar en la profundización de la liberalización económica, como propone Nicholas Lardy (2012), entre otros. Al respecto, conviene aclarar que la economía de la RPC ya es capitalista, aunque no en la definición actual, o sea, neoliberal; es más bien un tipo de capitalismo "orgánico", como el que prevaleció en su edad de oro, lo que implica una combinación entre la asignación de recursos vía señales de precios y tasa de ganancia, con la asignación "estatal". La integración a la economía global le impone a los chinos la disciplina del mercado, que el poder central intenta modular con las herramientas del intervencionismo del Estado.

La hipótesis que se sustenta aquí es que después de más tres décadas de acelerada transformación socioeconómica de la RPC y alcanzado el estadio que se señala arriba, se ha llegado a una encrucijada que exigirá impulsar un nuevo ciclo de reformas para lograr el equilibrio que exige ese tipo peculiar de capitalismo 
“orgánico". En ese camino, se plantean exigencias de mayor liberalización, que coexisten contradictoriamente con los esfuerzos por adecuar el intervencionismo estatal para alcanzar la frontera tecnológica. A su vez, la profundización de la reforma exige cambios en los mecanismos de ejercicio del poder.

El paradigma de la industrialización tardía, complementado con la vertiente institucionalista de la nueva teoría del desarrollo, constituye el eje del marco teórico, lo que posibilita recurrir a algunos conceptos clave del enfoque sobre aprendizaje tecnológico. Los alcances del artículo son limitados debido a las dificultades que implica proponer una interpretación de un proceso tan complejo que se encuentra aún en gestación. Varios aspectos, incluso de los más sobresalientes, como el Sistema Contractual de Responsabilidad Familiar y la reciente estrategia para alcanzar autonomía tecnológica, se abordan de manera sucinta y sólo se citan los datos que se consideran indispensables.

\section{LA COHESIÓN INSTITUCIONAL DESARROLLISTA}

La transformación de la RPC presenta paralelismo y contraste con la de Japón. China fue en la antigüedad uno de los imperios más poderosos y avanzados del mundo por más de mil años, antes de la Edad Moderna. A partir del siglo XV, con la dinastía Manchú, perdió capacidad de innovación y, aunque mantuvo su esplendor y siguió creciendo, lo hizo por medios extensivos (Buckley, 1996; Mokyr, 1993, cap. 9); su debacle se inició a partir de 1840 con la primera guerra del Opio, derivada de la confrontación con el imperialismo británico (Lovell, 2011). A inicios del siglo xIx, China producía el equivalente a un tercio del producto interno bruto (PIB) mundial, pero a continuación vino el descenso acelerado hasta estabilizarse, hacia fines de esa centuria, en alrededor de 5\% (Maddison, 2007; Yifu, 2012), porcentaje en el que permaneció hasta inicios de 1980. A partir de ese año, esa proporción se cuadriplicó gracias a las reformas.

Aún se debaten las causas de la aversión a la innovación tecnológica que pareció apoderarse de China después de 1500, pero su esclerosamiento político creciente lo hacía un país vulnerable al implacable avance industrial, tecnológico y militar de Occidente. Después de la primera derrota, en 1842, siguieron otras más que significaron términos humillantes de capitulación ante los británicos $\mathrm{y}$, luego, ante los japoneses (Lovell, 2011). En lugar de seguir el ejemplo de Japón, que con la reforma Meiji efectuó una asimilación selectiva de los métodos occidentales, las élites chinas, comenzando por la corrupta dinastía Quing, quedaron paralizadas por casi medio siglo. Hubo un despertar con la revolución comunista 
de 1949, pero la versión de modernización industrial instaurada por el maoísmo estaba también destinada a fracasar (Schell y Delury, 2013, cap. 10). Irónicamente, los maoístas, y luego Deng Xiaoping, tuvieron como fuente de inspiración la cosmovisión formulada por un puñado de intelectuales de fines del siglo XIX. ${ }^{1} \mathrm{Su}$ credo fue la recuperación del poder y la riqueza por medio de la asimilación selectiva de la tecnología occidental, pero sin sacrificar la idiosincrasia nacional. Esos principios los pusieron en práctica los tigres asiáticos en el último tercio del siglo $\mathrm{xx}$, imitando a los estrategas japoneses.

La narrativa convencional subraya, en la explicación del milagro asiático, los crecientes flujos de inversión extranjera directa, primero para ensamble de manufacturas intensivo en mano de obra (confecciones, calzado, radios, etcétera). Se ha documentado el pasaje a productos intensivos en tecnología por medio de acuerdos de subcontratación interfirma, que permitían a las empresas nacionales "aprender" de las empresas globales. Para sostener ese proceso, los gobiernos, presididos por una burocracia muy competente, invirtieron masivamente en educación y capacitación de la fuerza laboral, así como en infraestructura moderna.

Los resultados, sobre todo en Corea del Sur y Taiwán, se apreciaron de los ochenta en adelante, al convertirse en grandes exportadores de productos tecnológicamente avanzados. El planteamiento, anterior, aun simplificado al extremo, deja ver la calidad descriptiva de numerosos e importantes estudios, pero sin que posean capacidad explicativa, remitiendo a una pregunta obvia: ¿por qué tan pocos países se han encaminado en dirección a esa transformación fundamental?

Es evidente que el pequeño grupo de países aprendices exitosos de la tecnología occidental tienen en común la constitución de una coalición dominante (o élites) desarrollista ${ }^{2}$ que llevó a cabo una movilización social con fines de aprendizaje colectivo (en gran parte, por métodos autoritarios). Filipinas, Indonesia, otros países del sur de Asia y los de América Latina (con la posible excepción de Brasil), se encuentran en posición diametralmente opuesta, o sea, las coaliciones no son desarrollistas, sino más bien depredadoras (y autoritarias, a la

\footnotetext{
1. Se trata principalmente de Liang Qichao, Yan Fu y Chen Duxiu (Schell y Delury, 2013).

${ }^{2}$ Wade (1999, p. 70) subraya que lo decisivo está en los factores unificadores de la coalición de propietarios (llamado aquí "círculo de poder"): "Si encontramos [...] que el poder político está distribuido de manera pluralista $[\mathrm{sic}]$ o fragmentada, que diferentes constelaciones de grupos de interés, nacionales o extranjeros, ejercen presión sobre la política pública o si encontramos que el poder político está distribuido en torno a grupos que son hostiles a la industrialización, ésta está destinada a fracasar".
} 
par). Al carecer de la cohesión política necesaria, la riqueza en recursos naturales se convirtió en una maldición para la gran mayoría de la población, provocando una elevada desigualdad social y, por extensión, limitando los avances de la industrialización (Hoff y Stiglitz, 2004; Wade, 1999; Studwell, 2013; Acemoglu, Johnson y Robinson, 2004; Acemoglu y Robinson, 2014; Rivera, 2009).

Existiendo una modalidad fallida y otra exitosa de desarrollismo, se ha soslayado la presencia excepcional de fuerzas inductoras que modifican el patrón universal de ejercicio del poder, que es depredador (Evans, 1995). Los casos exitosos muestran invariablemente esa fuerza inductora, como sugieren Hoff y Stiglitz (2004), bajo la forma de una conmoción social, interna y/o externa. La crisis o conmoción social, si posee características de intensidad y duración, condiciona o determina la respuesta de las élites activando la movilización social orientada al desarrollo. ${ }^{3}$

Aceptando que los grupos que tienen el poder en un país atrasado condicionen la acumulación de su riqueza a un auténtico desarrollo socioeconómico, ¿el contexto internacional será conductivo, brindando mercados y acceso a capital y tecnología? Ésta es una cuestión largamente debatida en la economía política internacional y las interpretaciones están polarizadas. Las teorías y los análisis convencionales abocados al estudio de las relaciones internacionales asumen que los mercados de bienes y servicios están relativamente abiertos y que los países en desarrollo afianzarán su acceso a ellos conforme avancen en su industrialización. Se trata de una verdad a medias que soslaya la esencia de las relaciones internacionales, determinadas por el poder. Un ambiente externo conductivo para un país en desarrollo, que le brinde genuino acceso a la tecnología, al capital, así como a los mercados externos, es básicamente una concesión política de la potencia hegemónica mundial y se otorga en condiciones excepcionales.

Corea del Sur, en su calidad de aliado de Estados Unidos en la contención del comunismo en Asia Oriental, gozó de un trato altamente preferencial para recibir inversiones y tecnología, y luego para exportar manufacturas, pese a que provocó desplazamiento de empresas y desempleo en el país importador, o sea, Estados Unidos. La RPC logró acceso privilegiado en otras condiciones y por medios diferentes. Aún en los noventa parecía inconcebible que una nación con

${ }^{3}$ La teorización y el análisis histórico del papel de las élites en el cambio socioeconómico y político dentro del marco de esa dicotomía (desarrollistas vs. depredadoras), se encuentra en North (1984, cap. 3) y desarrollado más ampliamente en North, Wallis y Weingast (2009, cap. 1). 
una ideología y organización económica rival a la de Occidente pudiera contar con concesiones extraordinarias en materia tecnológica, comercial y financiera. La incorporación de la RPC a la globalización fue vista como una extensión lógica de la unificación del mercado mundial iniciada con la debacle de la Unión de Repúblicas Socialistas Soviéticas (URSS) y quedó ideológicamente justificada con la proclamación de "el fin de la historia", por parte de Francis Fukuyama (1992).

Empero, el proceso estuvo lejos de ser espontáneo, ya que tuvo poderosos promotores; éstos fueron los capitalistas chinos radicados en Hong Kong, Macao y Taiwán (Naughton, 2007), cuyo apoyo condujo a la admisión de la RPC en la Organización Mundial de Comercio (OPC) y al diluvio de inversiones, provenientes primeramente de Hong Kong y luego de las potencias occidentales y de Japón. El circuito continuó con la dramática reducción de los costos de manufactura global y, finalmente, con las enormes inversiones chinas en bonos del Tesoro de Estados Unidos, que contribuyeron a financiar el malogrado auge inmobiliario.

En cuanto a la fuerza inductora, la secuencia de desastres que experimentó la RPC maoísta a partir del fallido Gran Salto Adelante -específicamente, las hambrunas detonadas por la Revolución Cultural, con un terrible saldo de entre 28 y 45 millones de muertes (Jisheng, 2012)- provocó a la larga un cambio en la correlación política de fuerzas, que condujo paulatinamente al triunfo de la facción reformadora dirigida por Deng Xiaoping (Shirk, 1993). La élite dirigente, con Deng a la cabeza, cambió su estructura jerárquica, constituyendo lo que Susan Shirk (1993) llama el "Selectorado". Se trata de una coalición formada por los miembros del Comité Central del Partido Comunista Chino, los dirigentes revolucionarios retirados y los altos jefes militares, unas quinientas personas. El Selectorado establece una relación circular de poder, ya que Comité Central designa a los funcionarios del partido, del gobierno y del ejército que ingresarán al círculo de poder. Ese grupo, a su vez, tiene la autoridad para seleccionar a los jerarcas del Comité Central (Shirk, 1993).

Las medidas tomadas por los reformadores, sancionadas en diciembre de 1978, en la Tercera Plenaria del XI Congreso del Partido Comunista de China, indican que aprendieron de la historia, del fracaso de la extinta URSS y del potencial de las formas peculiares de autoritarismo desarrollista asiático, pero, sobre todo, de la inutilidad de la apuesta a la autarquía tecnológica que caracterizó al maoísmo.

Una vez liquidada políticamente la Banda de los Cuatro (los maoístas radicales) y depuesta la oposición de los maoístas moderados, como Hua Guo- 
feng (Shirk, 1993), comenzó la reunificación del Partido Comunista de China en torno al proyecto de modernizar la agricultura, la industria, la defensa nacional, la ciencia y la tecnología, llamado de "las cuatro modernizaciones". Habiendo acuerdo sobre la necesidad de introducir normas de asignación mercantil en el sistema de planificación, o economía de comando, se acordó que las medidas de mayor calado sólo se adoptarían si existía consenso en el Comité Central. Las tensiones ulteriores que provocó la profundización de las medidas liberalizadoras se atenuaron en gran parte gracias a la descentralización regional (construida, irónicamente, por Mao), a la experimentación flexible y a una sucesión de innovaciones institucionales que buscaban garantizar la estabilidad social (Yueh, 2010).

No habría que perder de vista que la cohesión político-institucional necesaria para profundizar un proceso de reforma puede debilitarse ante giros o conflictos inesperados. En tal caso, se puede hablar de una "disolución", absoluta o relativa, de la coalición; lo más frecuente es que la unidad desarrollista se vea debilitada cuando una parte de las élites intenta acaparar las rentas económicas que empiezan a resurgir. En el caso de la extinta uRss y los países de Europa del Este, que intentaban reformar o abandonar el socialismo, se decía que corrían el peligro de quedar atrapados entre el plan y el mercado (disolución absoluta). Como explica, entre otros, Wedeman (2003), hacia fines de los ochenta se produjo un impasse en la RPC al abrirse una ventana altamente lucrativa para desviar la producción planificada al naciente mercado. Brevemente, pareció que la reforma se colapsaba o que la única opción era el big bang (tratamiento de choque) (Aslund, 2007). Hubo una lucha, seguida de negociaciones que permitieron superar la disolución relativa; gracias a ello, quedó abierto el camino a la reestructuración de fondo de las empresas de propiedad estatal (EPE). El triunfo de los reformadores quedó sellado en 1992, con el llamado "tour de Deng" por la costa sur. ${ }^{4}$

Las alianzas se volvieron más estables a partir de 2000, a medida que se aceleraba el crecimiento económico. Un factor que favoreció la reunificación de las diversas facciones de la dirigencia del Partido Comunista, después de 1989, fue la descentralización, la autonomía regional y un gradualismo susceptible de

\footnotetext{
${ }^{4}$ Éste consistió en una gira por las principales zonas económicas especiales recien inauguradas en la costa sur de la RPC. El objetivo era hacerles publicidad para traer inversión externa, debido a la preocupación del Selectorado por la falta de respuesta de los inversionistas extranjeros. Wedeman (2003, cap.1) resume prolijamente el debate sobre la paralización temporal de la reforma china y las visiones de gradualistas y evolucionistas (adeptos al big bang), pero no logra una explicación convincente de cómo se rompió el impasse. Como se argumenta aquí, el tour de Deng fue clave al buscar la alianza con magnates de Hong Kong.
} 
rectificaciones de acuerdo con los resultados obtenidos, manteniendo lo que varios autores, entre ellos Naughton (2007), llaman el sistema de las dos vías, socialista y capitalista, que aún prevalece. ${ }^{5}$ Gracias a esos factores se evitó la repetición del drama de fines de los ochenta y el avance de la reforma coincidió con el pasmoso enriquecimiento de los dirigentes del partido. ${ }^{6}$

\section{LOS FUNDAMENTOS DE LA ESTRATEGIA DE INDUSTRIALIZACIÓN ACELERADA EN LA RPC}

Los reformadores chinos no se apegaron a una estrategia preconcebida y actuaron siempre con un enfoque pragmático y experimental, y con gran cautela, que al cabo de algunos años configuró lo que Lieberthal (2004) llama incertidumbre estructurada. El punto de partida fue firme y se basó en el reconocimiento de ciertos hechos clave: a) las bases del socialismo chino eran inoperantes para sostener, menos aún elevar, el nivel de vida de la población, que hacia fines de los setenta prácticamente no había mejorado en comparación con el existente en los cincuenta (Shirk, 1993; Yueh, 2010); b) en concordancia con lo anterior, se requerían incentivos mercantiles para aumentar la producción de bienes básicos y, luego, de la gama general, para elevar el nivel de vida; c) los logros de Japón, primero, y de los tigres asiáticos, luego, dejaban en claro los grandes lineamientos y exigencias del desarrollo tardío, y d) el cambio debía preservar la estabilidad tanto en la cúpula como en la base de la sociedad (esta última entendida esencialmente como el proletariado urbano-industrial).

La experiencia de los tigres asiáticos y Japón corroboró la centralidad de los factores político-institucionales, así como la dirección de las decisiones estratégicas, en el consabido sentido: a) desencadenar el potencial agrícola, esto es,

\footnotetext{
${ }^{5}$ Naughton (2007) supone incorrectamente que iniciado el siglo XXI se sigue una sola vía; se equivoca, ya que prevalece la propiedad estatal de la banca, los gigantescos monopolios estatales y no hay propiedad privada en el agro, sino una especie de arrendamiento extendido. Se trata de un sistema híbrido, pero inestable; parece claro que los líderes chinos tratarán de evitar a toda costa renunciar a su ideología original, que políticamente significa mantener el monopolio del poder. Para una explicación afín, véase Schell y Delury (2013). Sobre ajustes de cuentas internos en la cúspide del poder, Garnaut (2012).

${ }^{6}$ La diferencia crucial entre la exitosa reforma china y la fallida reforma de la extinta uRss radica en que en un caso el grupo, coalición o alianza a la cabeza del proceso se fragmentó y, en otro, permaneció unificado. Gorbachov y su facción apostaron a que el Partido Comunista se opondría a la reforma y, por ello, como parte de la "apertura", lo atacó frontalmente, llegando a declararlo ilegal; la fragmentación política llevó al caos y nulificó la reforma (Wedeman, 2003, cap. 1).
} 
aumentar la productividad en el campo para elevar el abastecimiento de materias primas y de alimentos, brindar un mercado a la industria y, a la par, reubicar la fuerza de trabajo en favor de la industria de exportación; b) dominar el arte de la manufactura a partir de la compra e imitación de la tecnología occidental, o sea, el aprendizaje tecnológico, creando o fortaleciendo las empresas nacionales, y c) poner el crédito al servicio de la industria, que exigió lo que en los sesenta se denominó "represión" del sistema financiero, implicando el control estatal del sistema bancario. Se abordará ahora la cuestión agrícola para tratar al aprendizaje tecnológico en el siguiente apartado y, posteriormente, el papel de las finanzas.

Marx, los clásicos y, más tarde, los estudios de la economía del desarrollo subrayaron, partiendo del caso inglés, la necesidad de comenzar la industrialización con la revolución agrícola, pero, con el argumento de "hacer un mejor uso del mercado mundial" (Little, Scitovsy y Scott, 1971), se alegó a partir de los sesenta que un país subdesarrollado podía importar alimentos baratos, exportando productos agrícolas exóticos y, posteriormente, manufacturas intensivas en mano de obra (véase la crítica de Bairoch, 1972). En realidad, ese argumento justificaba en la práctica la vigencia de la economía agroexportadora, con el latifundista y los inversionistas extranjeros como agentes dominantes, en enclaves dominados por estos últimos.

Los intentos nacionalistas de acabar con el legado de la vieja división internacional del trabajo tenían dos opciones. La primera, la reforma agraria radical, para expropiar a los latifundistas y fomentar la conversión del campesinado pobre en pequeños productores, apoyándolo con servicios de extensión, crédito agrícola y canales de distribución (Lipton, 2009). La segunda opción fue la que eligieron los revolucionarios del siglo xx (soviets y maoístas): la colectivización, con algunas variantes. En la RPC no se trató en rigor de granjas colectivas (la tierra no pertenecía al colectivo de campesinos), sino de comunas, donde trabajaban miles de familias distribuidas en unidades productivas, bajo órdenes y propiedad estatal (Shirk, 1993).

Se han discutido las causas del fracaso de la colectivización y todo indica que el mayor problema fue de gestión más que técnico. La industrialización socialista privilegiaba de manera desproporcionada la industria pesada, lo que limitaba recursos para fomentar la producción agrícola, de modo que para evitar el colapso del abasto a las ciudades, se sacrificó el ingreso que recibían los campesinos, que tenían que entregar volúmenes especificados a bajos precios fijados por el Estado (Shirk, 1993). Como era inevitable, se presentaron déficit recurrentes de producción, que se agravaron a fines de los cincuenta, provocan- 
do hambrunas, la más grave de las cuales fue la del periodo 1958-1962 (Jisheng, 2012). Los especialistas del equipo de Deng reconocieron lo obvio: que las comunas eran ineficientes e impopulares y que la reforma debía empezar por el sistema comunal.

Las primeras medidas que aprobó el Comité Central fueron más bien cautelosas, centrándose en reducir las entregas obligatorias y elevar levemente los precios (Yueh, 2010). Los campesinos empezaron a actuar por cuenta propia, con apoyo de funcionarios de bajo rango, experimentando hasta llegar a un sistema en el que las familias tomaron el control de las parcelas, bajo un arreglo contractual de volumen y precio en función del resultado de las cosechas (Naughton, 2007, p. 89). Al cabo de un par de años, el Comité Central cedió a la presión de los campesinos y en 1984 se instauró el Sistema Contractual de Responsabilidad Familiar (SCRF) (Naughton, 2007). Éste fue el origen del sistema de las dos vías -que ha mutado al transferirse a la industria y a la banca- vigente hasta la fecha. Los derechos ganados en la parte mercantilizada de la economía se reconocieron como derechos de propiedad informales que se fueron "occidentalizando" conforme la RPC se integraba más ampliamente a la economía global, hasta culminar con la reforma de 2004 a su Constitución, que reconoció la legitimidad de la propiedad privada.

El acelerado despegue industrial habría sido imposible sin el espectacular incremento de los rendimientos en granos (arroz, maíz y trigo) y caña de azúcar (Studwell, 2013, pp. 185-187). ${ }^{7}$ Como era de esperarse, el incremento de la productividad posibilitó un éxodo masivo del campo a la ciudad, pero los migrantes enfrentaron restricciones que disuadieron una mayor afluencia; lo anterior se debió a que siguió vigente el sistema hukoi, es decir, el registro y retención de la población por su lugar de nacimiento, con derechos diferenciados para los de origen urbano en comparación con los de origen rural. Con base en ese sistema, el poder central controló el flujo de trabajadores provenientes del campo, que se convirtieron en una suerte de ciudadanos de segunda clase, sin derechos de residencia urbana permanente, ni servicios de salud o educación. El mantenimiento del método de registro obedece a factores complejos, pero benefició a los trabajadores urbanos, cuyo apoyo tácito se consideraba central para darle continuidad a la reforma. Otra consecuencia de mantener el hukoi fue la aceleración en el in-

\footnotetext{
${ }^{7}$ Desafortunadamente, como explica Studwell (2013), desde fines de los noventa, el apoyo al agro se diluyó y la brecha campo-ciudad comenzó a ampliarse aceleradamente, lo que explica el creciente índice de desigualdad que ha caracterizado la reforma china (el coeficiente de Gini pasó de 0.3 a 0.45$)$.
} 
cremento de los salarios, ya que no se formó propiamente un ejército industrial de reserva.

Meng (2014), con datos oficiales chinos señala que durante el periodo 2000-2009, sólo entre 20\% y 23\% de la fuerza laboral urbana se reubicó permanentemente en las ciudades; de esos últimos, el tiempo promedio de residencia fue de siete años. Al discutir si la RPC llegó al punto de inflexión de Lewis, algunos autores, por ejemplo, Yao y Zhang (2010), han sugerido que una reducción de las restricciones a la migración hubiera fácilmente duplicado la disponibilidad urbana de trabajadores. Sin embargo, parece ser que la estrategia idónea para elevar el nivel de vida de la población fue la combinación adoptada, pese a que el incremento de los salarios rurales se rezagó en comparación con los urbanos ( $\sin$ mencionar las condiciones precarias de los migrantes). Las restricciones migratorias, aunque contradicen la ideología liberal, también contribuyeron a acelerar el tránsito a las industrias intensivas en capital y en conocimiento. ${ }^{8}$

El SCRF sirvió de modelo para comenzar la reforma de las EPE. Por medio del sistema, se permitió, primeramente, que los gerentes gozaran de cierta autonomía, reteniendo parte de la producción para su venta en un mercado, mientras que otra parte era de entrega obligatoria al Estado. La reforma pudo detenerse aquí, como apunta Wedeman (2003), ya que se desencadenó una lucha política, debido a que esta reforma parcial incurrió en lo que Kornai (2008) había previsto: déficit crecientes de las EPE, inducidos por la seguridad de que el Estado los asumiría mediante una atenuación de las restricciones fiscales (soft budget constrain). Este fue el momento de la verdad, ya que quedaron en evidencia no dos, sino tres opciones: a) pasar del gradualismo al big bang; b) detener e, incluso, revertir la reforma, como sucedió recurrentemente en Cuba, y c) ahondar la reforma por vía gradual, pero con crecientes repercusiones políticas.

La derrota del bloque conservador de Li Peng abrió el camino a la tercera, por lo que se procedió a liquidar masivamente al sector de EPE y, a la vez, a desligarlas del subsidio estatal, para que dependieran del crédito de un sistema bancario también sometido al tratamiento de la doble vía. Empero, no sucedió lo esperado por asesores y observadores occidentales, es decir, la liquidación total de las EPE. Un centenar fueron reorganizadas con apoyo de los grandes bancos de inversión de Wall Street, para servir como instrumento de política industrial y

\footnotetext{
${ }^{8}$ Entre 1978 y 2010, el ingreso disponible per cápita en las ciudades se elevó 7.6 veces en términos reales; en tanto, el ingreso rural neto per cápita real se elevó 7.4 veces en el mismo periodo; se trata del más asombroso incremento de los ingresos de los trabajadores registrado en la historia (Zongsheng, 2014).
} 
concentración de poder económico (Walter y Howie, 2011). La contraparte de la reorganización de las EPE fue la liberación del régimen de las empresas privadas, cuyo número e influencia creció explosivamente. Éstas, aunque frecuentemente con participación accionaria del Estado, son las principales protagonistas de la estrategia para crear un sector de alta tecnología, como se verá más adelante.

El sistema bancario se sometió a la liberalización, limitando su alcance a través de la "represión financiera", el control de la cuenta de capital y la canalización de un enorme ahorro popular. La liberalización se aceleró con la adhesión a la OMC, incluyendo el derecho a la participación accionaria minoritaria de extranjeros. Primero, el que había sido el banco único, el Banco del Pueblo, se convirtió en banco central y se crearon otros cuatro especializados. Al lado de ellos están tres bancos de desarrollo, un gran banco de inversión, un segundo grupo de bancos estatales que surgieron como sociedades por acciones y una red de más de 200 bancos extranjeros.

En la medida que al inicio de la reforma el sistema bancario estaba atrapado en la atenuación de las restricciones fiscales, financiando las crecientes pérdidas del sector de EPE, la liquidación de la enorme cartera de préstamos incobrables que, de acuerdo con Yueh (2010), era casi de 20\% del PIB a inicios del siglo XXIexigía cerrar miles de EPE. El círculo vicioso se podría convertir en uno virtuoso en tanto se superara la resistencia política de los sectores conservadores, mostrando la viabilidad de la doble reforma. En cierto modo, la reforma bancaria era un vértice que unificaba los ejes de las otras iniciativas: el aumento de las exportaciones, la exitosa introducción del SCRF, más la atenuación de flujo migratorio mediante el hukoi, y la formación de un amplio estamento de monopolios.

En lo formal, la banca opera razonablemente bajo los lineamientos de la buena gobernanza global y las restricciones que favorecen al Estado están sólidamente establecidas. El régimen de tasas de interés no está completamente liberado y hay ciertas restricciones que limitan la salida de capitales. Pero, sobre todo, en la medida en que el Estado es accionista mayoritario o principal de la mayor parte de los bancos, los enormes depósitos están bajo su control.

\section{Inserción en la economía global: de la fábrica global a la búsqueda de autonomía tecnológica}

La inserción de la RPC en la economía global como "industrializador tardío" ha pasado por tres etapas que tienden necesariamente a traslaparse: a) la fábrica global, b) el aprendiz tecnológico avanzado y c) el giro hacia la autonomía tecnoló- 
gica. El hecho de que empresas chinas produzcan bienes tecnológicamente avanzados no significa que haya dejado de ser un centro de ensamble, empaque y prueba de productos en multitud de sectores como el de la confección, el electrónico, el automotriz y el de circuitos integrados. Gracias al relevo industrial, el crecimiento de la productividad laboral ha sido extraordinario; entre inicios y mediados de los noventa, coincidiendo con la política de "puertas abiertas", se aceleró de tal modo que el producto por trabajador se multiplicó por siete, en comparación con el triple en la India. No obstante, la productividad en la RPC es de poco menos de 15\% que la de Estados Unidos (Yueh, 2010). Se discutirán a continuación la constitución y las tendencias más notorias de cada etapa.

\section{a) La fábrica global china}

Ésta consiste en la agrupación masiva de plantas de ensamble en las decenas de zonas económicas especiales situadas en la costa sur; la inversión extranjera se concentra en la provincia de Guangdong (en el delta del río Perla, colindante con la ciudad de Shenzhen) y en el delta del Yangtsé (que comprende Shanghái y parte de la provincia de Jiansu). En ambas áreas, las filiales de transnacionales, asociadas o no con empresas chinas, importan partes y componentes que se ensamblan o se someten a un mayor procesamiento para su reexportación.

La mayor inversión extranjera directa provino primeramente del "círculo chino", o sea, el área de integración entre la parte continental con Hong Kong y Taiwán, además de Japón (Greaney y Li, 2009). Hong Kong y Taiwán comenzaron una transferencia masiva de industrias intensivas en trabajo, como las de calzado, confección y juguetes, proceso que se completó básicamente a comienzos de los noventa (Naughton, 2007). A continuación, vino la transferencia de la industria electrónica, en sucesivas oleadas, así como la de computadoras y accesorios y, más tarde, la del subsector de notebooks, en la década de los noventa, procedente de Estados Unidos, Japón y Taiwán (Dedrick y Kraemer, 2008). En la primera década del siglo XXI, siguieron los equipos de telefonía móvil (Ernst, 2010; Harwit, 2008), maquinaria y equipo de transporte.

La posición de la RPC en las redes globales de subcontratación adopta un perfil tridireccional. Hong Kong es, de lejos, el principal inversionista, pero el proveedor tecnológico es Japón, seguido por Taiwán y Corea del Sur (Dean, Lovely y Mora, 2009). Estados Unidos actúa también como proveedor tecnológico, siendo a la vez el principal mercado de los productos que se ensamblan o procesan en la RPC. De acuerdo al código aduanero chino (Ma y Li, 2004), existen, 
como en otros países, dos regímenes para ensamble y transformación a fin de exportar. En ambos se debe exportar la totalidad de la producción, que puede contener insumos nacionales (Koopman, Wei y Wang, 2008):

1) Procesamiento y ensamble: la propiedad de los insumos importados es de la firma extranjera.

2) Procesamiento con insumos importados: la propiedad de los insumos es de la empresa local.

El cuadro 1 indica las exportaciones totales y la participación de los dos principales socios comerciales. Señala también las dos modalidades de comercio de procesamiento. En 1994, la RPC exportó un total de USD 100200 millones para pasar a la impresionante cantidad de USD 1582700 millones en 2011. Estados Unidos es el principal mercado, ya que absorbe casi $18 \%$ de las exportaciones chinas. En importaciones, los papeles se invierten debido a que del total de USD 1451100 millones correspondientes a 2011, Japón proporcionó casi 15\%, contra menos de 5\% de Estados Unidos. En los noventa, la RPC exportaba principalmente una amplia gama de manufacturas livianas, sobre todo textiles y calzado, que representaban poco más de $80 \%$ del total. La composición comenzó a cambiar rápidamente a partir de 2000 , para que se volvieran predominantes maquinaria y equipo de transporte, que en 2011 llegaban casi a 40\% (gráfica 1).

Hasta 2000, las empresas conjuntas (joint ventures) fueron la forma mayoritaria de inversión extranjera, pero después de la adhesión de la RPC a la OMC la composición cambió; las empresas conjuntas se redujeron hasta una quinta parte y la inversión totalmente extranjera fue mayor a 70\% (Walter y Howie, 2011). La más amplia libertad en el régimen de inversión extranjera le imprimió mayor impulso, ya que su monto neto se multiplicó por cinco entre 2000 y 2012 , cifra record en el mundo (OMC, 2014).

\section{b) El aprendiz tecnológico avanzado}

Hacia fines de la década de los noventa y los primeros años del siglo XXI, la fábrica global china, aunque conservaba cierto margen de rentabilidad, ${ }^{9}$ había

\footnotetext{
${ }^{9}$ Con datos del Buró de Estadísticas de la RPC, Lardy (2012, p. 149) calcula que el retorno por ventas en la industria de exportación de confecciones y calzado era de un modesto $4.3 \%$ en 2005 , pero se incrementó a $6 \%$ en 2009 , gracias a las mejoras en la productividad.
} 


\begin{tabular}{|c|c|c|c|c|c|c|c|c|}
\hline$\overbrace{N}^{2}$ & 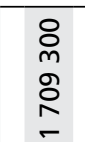 & $\begin{array}{l}\stackrel{8}{0} \\
\stackrel{m}{2} \\
\stackrel{N}{N} \\
\stackrel{-}{N}\end{array}$ & $\begin{array}{ll}8 & 8 \\
\text { ¿ } & 8 \\
\text { నิ } & \text { ิ }\end{array}$ & 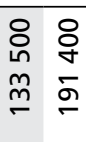 & 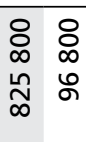 & $\begin{array}{l}8 \\
\stackrel{0}{0} \\
\hat{\Lambda} \\
6\end{array}$ & 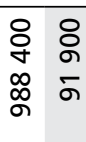 & $\begin{array}{l}\stackrel{8}{0} \\
\stackrel{0}{0}\end{array}$ \\
\hline$\delta^{V}$ & 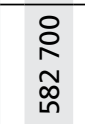 & $\frac{8}{\frac{8}{6}}$ & $\begin{array}{ll}8 & 8 \\
\grave{1} & 0 \\
\stackrel{1}{N} & 0\end{array}$ & 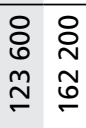 & $\begin{array}{ll}8 & 8 \\
0 & 8 \\
0 & \$ \\
& \infty\end{array}$ & $\begin{array}{l}8 \\
8 \\
8 \\
0 \\
0\end{array}$ & $\begin{array}{ll}8 & 8 \\
0 & 0 \\
1 & \kappa \\
\infty & 1\end{array}$ & $\begin{array}{l}8 \\
8 \\
m \\
m\end{array}$ \\
\hline
\end{tabular}

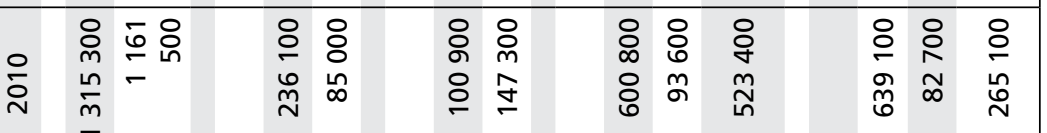

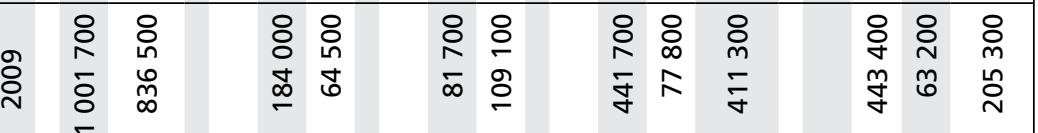

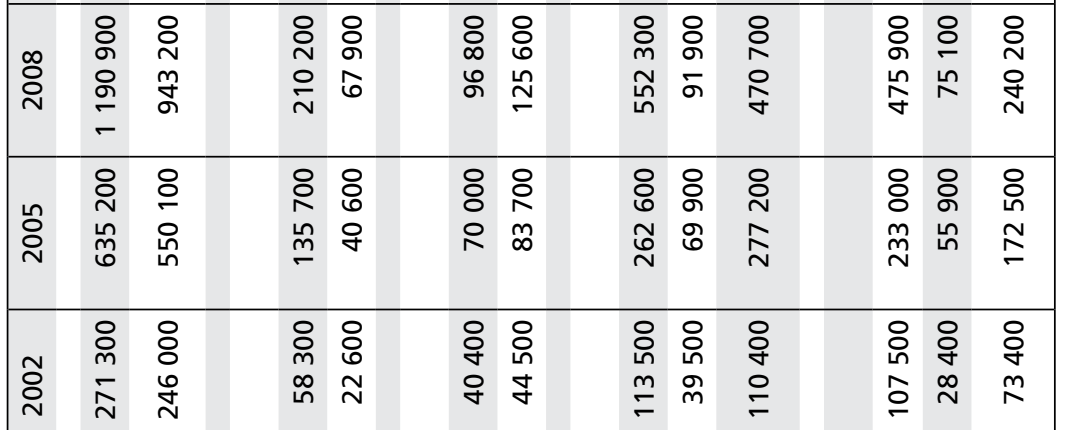

$\widetilde{0}$

৪ :

స

กิ่ กิ

이요 这

竎

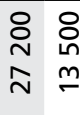

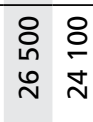

ㅇํㅇํํㅇํ

ㅇํํ 워 음

นิ స

m $₹ \bar{\sigma}$ 
Gráfica 1. Composición de las exportaciones manufactureras de la RPC, 1993-2011

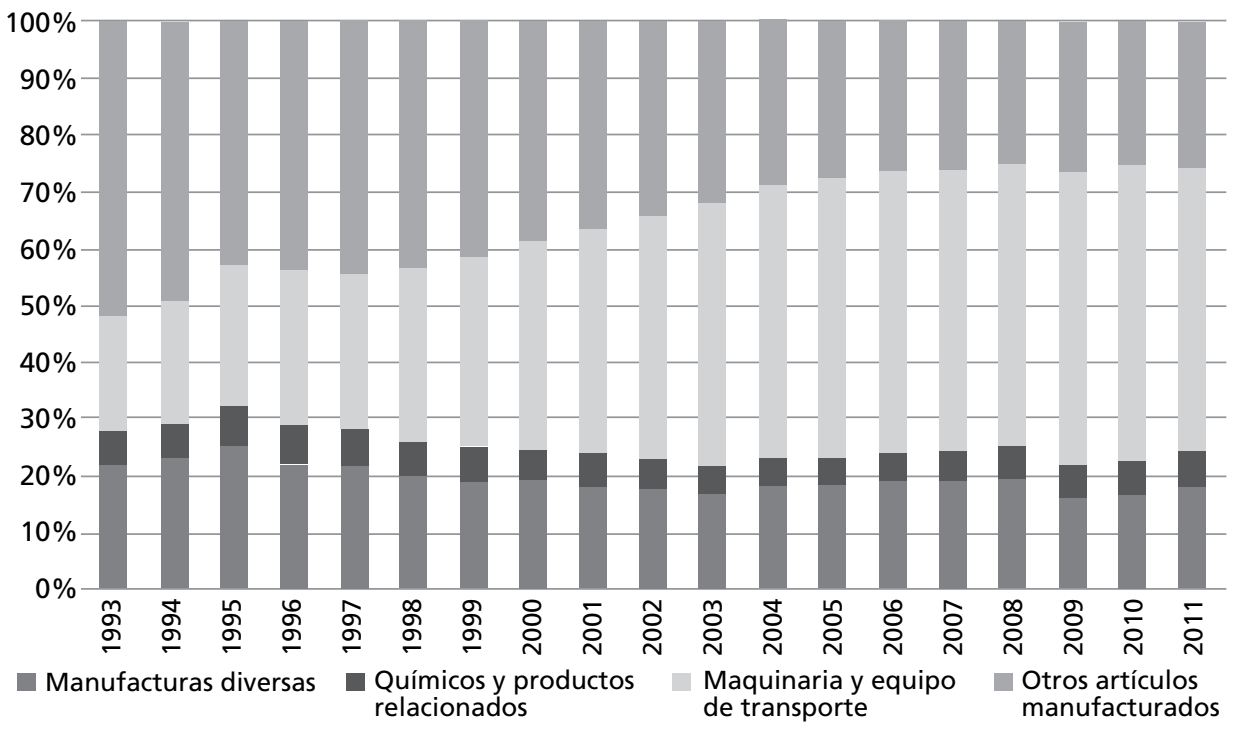

Fuente: Elaboración propia con datos de Internet Securities, Inc. (ISI Emerging Markets), China Premium Database.

agotado su potencial como fuente de crecimiento económico, ganancias internacionales y medio de transferencia de tecnología (Ernst, 2010). Lo obtenido por las empresas chinas en poco más de una década de participación subalterna en las redes globales había sido sustancial, pero estaban subordinadas a las empresas líderes de Estados Unidos y Japón. La gama principal de productos, los electrónicos de consumo de primera generación, se había convertido en commodities y el margen de ganancia era raquítico.

El cambio de estrategia, llamado por Ernst (2010) de diversificación, consistió en enfocarse en productos y servicios con mayor valor agregado (esto es, rentas económicas internacionales ${ }^{10}$ y un contenido tecnológico superior. Pero en vista de la inferioridad ante los líderes globales, lo anterior implicaba

\footnotetext{
${ }^{10}$ En el proceso de importar para exportar, la ganancia económica para el país está en la diferencia entre los dos valores, o sea, las exportaciones netas; la asociación (joint ventures) entre empresas nacionales y extranjeras en la redes de abastecimiento global puede implicar la transferencia de tecnología. Se ha discutido exhaustivamente la idoneidad de este canal de transferencia y el punto de vista que ha prevalecido es que más allá de un punto, que se asocia a la absorción de procedimientos corporativos básicos, los beneficios son modestos (Amsden, 1989; 2001).
} 
situarse detrás de la frontera tecnológica, como innovadores de "segunda generación" (Ernst, 2010). El aspecto más sobresaliente de la diversificación fue lo que Gereffi et. al. (2001) llaman up grading (escalamiento industrial) funcional en las redes globales de producción, participando en la elaboración de productos más complejos y con asociación en "módulos" de diseño (Ernst, 2010). Sin embargo, otro aspecto central, complementario con el anterior, fue la drástica elevación de las capacidades de producción e innovación incremental y arquitectónica (redefinición del producto), para competir contra las empresas extranjeras en el abastecimiento del mercado interno. Dos de los principales ejemplos son los rubros automotriz y de autopartes, y de equipo móvil de telecomunicación, que se analizarán brevemente. Pero antes es necesario discutir algunos aspectos de la conversión de la RPC en aprendiz tecnológico.

Una primera cuestión es la distancia a la que se halla el promedio de las empresas chinas de la frontera tecnológica. ${ }^{11}$ Aun si la estimación se limita a los sectores que constituyen la avanzada de la información y la comunicación, es difícil proponer una medida que se considere precisa. Siguiendo a Ernst (2010) y Breznitz y Murphree (2011), las empresas chinas, en promedio, están entre treinta y cuarenta años detrás del líder (Estados Unidos), especializándose en productos de segunda generación, con insuficiente capacidad de diseño y aún con sustanciales limitaciones en la formación de trabajadores del conocimiento (Ernst, 2010). A medida que la RPC avanza hacia la frontera tecnológica, ésta naturalmente se desplaza, de modo que, como subrayan Breznitz y Murphree (2011), es como la carrera de la Reina Roja del relato de Lewis Caroll.

Pese a situarse detrás de la frontera tecnológica y ser dependiente de la tecnología occidental, la RPC puede gozar por un largo plazo, como señalan Breznitz y Murphree (2011), de tasas comparativamente altas de crecimiento, no sólo porque hay margen relativamente amplio para elevar la productividad sin introducir productos y procesos radicalmente nuevos, sino porque, gracias al cambio introducido por la producción global, las empresas chinas pueden especializarse rentablemente en segmentos de la cadena global de valor. Estos autores también explican que para aprovechar la innovación de segunda generación,

\footnotetext{
${ }^{11}$ No hay que perder de vista que aun los países más exitosos de desarrollo tardío, como Taiwán y Corea del Sur, están detrás de la frontera tecnológica y todavía se debate si lograrán cerrar finalmente esa distancia. Corea del Sur y Taiwán tienen avances significativos, pero aún limitados, en un sistema complejo de producción (SCP), dominado exclusivamente por las empresas de países desarrollados, principalmente de Estados Unidos Sobre los avances de las empresas coreanas en un SCP para telecomunicaciones, véase Park (2012).
} 
la RPC ha creado dos sistemas de innovación: uno nacional, controlado por el gobierno central, y otro regional, que comprende Pekín y Shanghái y en menor medida el delta del río Perla (Breznitz y Murphree, 2011). Al fragmentarse la producción, las empresas chinas se especializan rentablemente en segmentos específicos de la cadena de valor global. A su vez, diversas compañías, como Lenovo y Huawei, han formado sus propias redes regionales, lo que les permite capturar rentas económicas de organización. ${ }^{12}$

Pese a las posibilidades de crecer detrás de la frontera tecnológica, la barrera que enfrentan las empresas chinas más avanzadas es la persistencia informal del sistema danwei ("unidades de trabajo"). También conocido como "el tazón de hierro", implicaba en la era maoísta la autosuficiencia, ya que la provisión de todos los servicios públicos, incluso el racionamiento de bienes de consumo, se efectuaba por unidad de trabajo (Naughton, 2007). Este sistema se abolió, pero subsiste la mentalidad danwei, o sea, la tendencia de los trabajadores, incluso los de más alta calificación, a formar alianzas o tribus para acaparar recursos, en pugna o competencia con grupos similares. Breznitz y Murphree (2011) señalan la cultura danwei como el principal obstáculo en la formación de redes de conocimiento en los conglomerados como el del distrito de Haidian.

En lo que respecta a los sectores para abastecer el mercado interno, se abordará primero el automotriz. La decisión de crear una industria nacional moderna en ese ramo se tomó tempranamente, desde los ochenta, con la forma de una empresa conjunta entre una compañía estatal y una multinacional. ${ }^{13}$ La mayor parte de los productos automotrices existentes eran camiones y autobuses, más una pequeña parte de automóviles de diseño y producción obsoletos, con tecnología soviética. El objetivo del Estado chino era atraer a una o varias multinacionales, preferentemente japonesas, para que produjera un vehículo exportable a los grandes mercados. Ante la negativa de los japoneses, negociaron con American Motors Corporation y con Peugeot; ambos proyectos fracasaron porque sólo aceptaron transferir el ensamble de vehículos pasados de moda, los modelos llamados "africanos y árabes", sin una red local de abastecimiento.

En cambio, el acuerdo con Volkswagen, que comenzó a negociarse a fines de los ochenta, fue exitoso, culminando con la Shanghai Automotive Indus-

\footnotetext{
${ }^{12}$ Para definir la capacidad competitiva de las empresas se utiliza la propuesta de Kaplinsky (2005) de rentas económicas (o sobreganancias) internacionales, diferenciando sus distintas fuentes; lo anterior se complementó con el concepto de rentas económicas de aprendizaje tecnológico, propuesto por Dabat, Rivera y Sztulwark (2007).

${ }^{13}$ Lo que sigue, en materia de industria automotriz, procede de Chin (2010).
} 
trial Corporation (SMC), que, después de numerosas salidas en falso, dio lugar a una red local de proveedores de partes y componentes con $90 \%$ de procedencia china. La formación de una red de abastecimiento local tomó cerca de diez años y no estaba contemplada en los acuerdos originales con la casa matriz de Volkswagen. La compañía alemana accedió a transferir tecnología y conocimiento de procesos técnicos para dicha red, considerando su posición competitiva global y el potencial del mercado chino. El éxito no se explica únicamente por la decisión de la firma de transferir tecnología de última generación, sino por la capacidad de absorción de la economía receptora. Ello requirió de un enorme esfuerzo que combinó las virtudes del sistema de doble vía, en el marco de lo que hemos llamado cohesión institucional.

Compañías independientes como Chery y Faw comenzaron su desarrollo en los noventa, gracias a los avances logrados en la red doméstica de proveedores de SMC. Utilizaron métodos tanto ortodoxos como heterodoxos de transferencia de tecnología de compañías extranjeras. Sin embargo, los automóviles de las marcas chinas carecen hasta la fecha de la calidad para competir en los mercados desarrollados, aunque representan una forma de evitar que las transnacionales tomen el control total del mercado interno.

En telecomunicaciones, el éxito de zTE y Huawei combina factores complejos. ${ }^{14}$ La RPC mantuvo hasta fecha reciente grandes compañías estatales proveedoras de servicios de telecomunicaciones a las que obligó a competir para que elevaran su eficiencia y abatieran sus precios, a la vez que mantuvo hasta 2001 barreras a la participación extranjera. Otros factores fueron la acelerada expansión de la infraestructura de la industria a cargo del Ministerio de Correos y Telecomunicaciones y que, aun bajo las reglas de la oMc, la entrada de compañías extranjeras fue muy limitada. ZTE y Huawei se apoyaron en los beneficios de la asociación establecida entre la estatal Datang y la Academia China de Tecnología en Telecomunicaciones, que introdujo su propio estándar de tercera generación (TD-SCDM), para transmisión móvil de datos a alta velocidad. ZTE es estatal, pero gestionada de forma privada. Huawei es privada, pero obtuvo el apoyo estatal para expandirse, nacional e internacionalmente.

Ambas empresas de equipo de telecomunicaciones, además de abastecer el mercado doméstico, pueden considerarse ejemplos de aprendizaje tecnológico avanzado; no obstante, dependen de los procesadores, sistemas operativos y, en general, del software de aplicación de las empresas occidentales. Sólo Huawei

\footnotetext{
${ }^{14}$ Lo que sigue procede de Harwit (2008).
} 
ha comenzado a ingresar a los mercados avanzados como un proveedor muy competitivo de equipo genérico.

\section{c) El giro hacia la autonomía tecnológica}

El eje del naciente sistema de ciencia y tecnología de la RPC que empalmaría los avances en aprendizaje con el pretendido salto tecnológico es Pekín, que concentra los centros formativos y de investigación, así como los mayores contingentes de trabajadores del conocimiento. El modelo general adoptado por los estrategas chinos para esa ciudad, y en menor medida para Shanghái, consiste en potenciar las llamadas capacidades de absorción de las empresas domésticas, mediante inversión masiva en educación superior, infraestructura e investigación y desarrollo adaptativos, favoreciendo la formación de nuevas empresas ligadas a las universidades y centros de investigación, sobre todo a la prestigiada Academia China de Ciencias (Breznitz y Murphree, 2011). Las universidades y los laboratorios están aglomerados principalmente en el distrito de Haidian, al noreste de la ciudad. Colindante con ese conglomerado se encuentra el parque científico de Zhongguancun, que es el eje de la planificación tecnológica y se orienta principalmente al desarrollo de software (Breznitz y Murphree, 2011).

Hacia mediados de la primera década del siglo XXI se produjo un cambio que puede reorientar las actividades de Pekín. Como resultado de los avances previos en subcontratación internacional, exportaciones ordinarias y producción para el mercado interno, la RPC se convirtió en el principal mercado del mundo de semiconductores, con 56\% del consumo hacia 2005. A su vez, un tercio de las exportaciones chinas utilizan semiconductores como componentes (Ernst, 2014). A eso hay que añadir que en los últimos años, la RPC se ha convertido en el mayor mercado de teléfonos celulares en el mundo, con empresas nacionales sólidamente posicionadas (China Mobil en calidad de intermediario, Huawei y ZTE como productores de equipo de telecomunicaciones, $\mathrm{y}$ Xiaomi ${ }^{15}$ como proveedor de telefonía celular).

\footnotetext{
${ }^{15}$ Se trata de un emprendimiento que se ha convertido en el tercer fabricante de teléfonos celulares del mundo; sus tres propietarios -Lin Bin, Lei Jun y Zhou Guangping- son, al igual que los de Lenovo, descendientes de prominentes miembros del Selectorado; la gran mayoría de los quinientos millones de usuarios de teléfonos celulares usan un Xiaomi, cuyo modelo básico cuesta menos de USD 40 (Clover, 2014). A primera vista, se trata de un ejemplo de iniciativa privada, pero es más bien un producto de la coordinación estatal. El procesador utilizado en los primeros modelos fue proporcionado por MediaTek, compañía taiwanesa, y el ensamblado se efectúo en Shenzhen. Pos-
} 
En junio de 2014 el gobierno chino expidió los "Lineamientos para promover el desarrollo nacional de la industria de circuitos integrados" (Ernst, 2014). El objetivo es sobrepasar en ese vital componente (o familia de componentes) la fase de acercamiento a la frontera (catching up) para competir con los líderes globales en un sector que se ha desintegrado verticalmente. La mayoría de las empresas globales tipo first mover advantage (casi exclusivamente estadounidenses) se han especializado en diseño de circuitos integrados más avanzados, sean de funciones lógicas, genéricos (como los microprocesadores) o específicos (ASCI); los second movers, situados en Asia Oriental (Samsung, TSMC, MediaTek) se han especializado en circuitos de memoria (tipo DRAM), la manufactura de obleas electrónicas, en diseño modular o diseño/manufactura de procesadores de tecnología intermedia.

La RPC tiene un avance significativo pero limitado en diseño y manufactura. ${ }^{16}$ En manufactura de obleas, los fabricantes chinos se encuentran dos generaciones atrás de los líderes mundiales, que son Intel (que no desintegró su diseño de manufactura), Samsung (no desintegrada), TSMC y Hynix. Entre las firmas taiwanesas, TSMC tiene $60 \%$ del mercado mundial, contra $5 \%$ de la principal empresa china, SMIC, o sea, menos de la décima parte de su competidor taiwanés. En diseño hay varias empresas que han logrado sobresalir, como Tsinghua, Spreadtrum y RDA, que están controladas accionariamente por el Estado. RDA emplea ingenieros formados en universidades chinas para diseñar circuitos de bajo costo. Por su parte, Spreadtrum combina la manufactura de obleas con incursiones en soluciones de software.

El salto a la frontera exige capacidades diferenciadas en la manufactura en comparación con el diseño. En la manufactura de las obleas, se deben solucionar principalmente problemas de escala de producción, coordinación de proyectos complejos y dominio de una tecnología (de trailing node) que evoluciona más bien de forma incremental y cuyos bienes de capital y herramientas son obtenibles en el mercado mundial. En cambio, el diseño de circuitos integrados es altamente intensivo en conocimiento, la mayor parte del cual es tácito; los obstáculos para ingresar al campo son elevados y los acuerdos contractuales o las empresas conjuntas, muy restrictivos en cuanto a transferir conocimiento tecno-

teriormente las compañías chinas de diseño en circuitos integrados se han enfocado a mejorar el diseño de hardware (Ernst, 2014).

${ }^{16}$ La información de este párrafo procede de Ernst (2014); el análisis subsiguiente se inspira en su interpretación del programa en semiconductores, excepto en la evaluación de las capacidades de absorción en diseño de circuitos avanzados. 
lógico, como en el caso de la fallida asociación Apple-Samsung. En función de lo anterior, las empresas chinas deben desarrollar primeramente elevadas capacidades de absorción, en asociaciones formales con los líderes del ramo, como Qualcomm, Intel y Apple, para luego pasar al farragoso conflicto de patentes. La estrategia del gobierno chino, de fomentar una alianza estratégica con Qualcomm, se apoya en un enorme mercado que podría ser en unos tres años de mil millones de usuarios de telefonía móvil.

Como se advierte, los desafíos son formidables y requieren una modalidad de intervención pública no autoritaria y más flexible que se adecue a la realidad de la producción en redes globales, lo cual exige también asociación y coordinación con diversidad de empresas que, a su vez, son proveedores y compradores. La primera pregunta que se hacen los especialistas es, por lo tanto, si esto es indispensable y si debe convertirse en prioridad nacional, como lo anunciaron recientemente las autoridades. Una vez que se advirtieron las limitaciones de la fábrica global, el objetivo de la alta dirigencia fue el salto a la frontera tecnológica, por motivos de seguridad nacional (principalmente en ciberseguridad) y para contrarrestar la desaceleración del crecimiento económico (tema que se aborda en el siguiente apartado).

La segunda pregunta central se refiere a las perspectivas de éxito. La experiencia de la RPC ha invalidado numerosos supuestos sobre los obstáculos al aprendizaje tecnológico y ésta podría ser otra sorpresa. El problema es, sin embargo, la superioridad tecnológica de Estados Unidos. La cuestión no radica solamente en el sistema de ciencia e ingeniería, sino más en general en el sistema institucional estadounidense, que favorece al máximo las olas de destrucción creativa en una medida que no existe en Alemania y Japón, como explican Hall y Soskice (2001), países que son, a su vez, los referentes de la RPC. ${ }^{17}$

Se discutirán ahora, brevemente, los desequilibrios macroeconómicos provocados por al auge exportador, enfatizando el aspecto más inquietante: la disminución de la tasa de crecimiento anual del PIB, de poco más de $10 \%$ a $7 \%$ anual, a partir de 2011 .

${ }^{17}$ La cuestión medular es si la introducción de una tecnología con efectos sociales potencialmente disruptivos debe estar condicionada al consenso social. De acuerdo con Hall y Soskice (2001), el sistema institucional alemán y japonés se caracteriza por la búsqueda de un equilibrio entre el cambio tecnológico y la estabilidad social; en consecuencia, en ambos países, y en aquellos que los toman como modelo, son menos probables los cambios radicales. 


\section{LOS RETOS DEL CRECIMIENTO LIDERADO POR LAS EXPORTACIONES Y LA INVERSIÓN}

Una economía que se ha expandido a tasas elevadas por tres décadas o más tenderá a experimentar una disminución de ese ritmo por dos causas. Una es estadística y se debe a que los incrementos absolutos anuales del producto se comparan con una producción acumulada mayor. La otra tiene que ver con el mecanismo interno de formación de capital, pero está a discusión la definición de la amplitud de este fenómeno.

Aunque la teorización es insuficiente, la evidencia empírica es abundante y señala que con posterioridad a 1950, diversos países en desarrollo, después de experimentar varias décadas de crecimiento sostenido, sufren una desaceleración o estancamiento (Felipe, 2012). Algunos autores (Asian Development Bank, 2011) hablan de una trampa, esto es, una suerte de barrera que obstaculiza el ascenso a un nivel superior de desarrollo. Eichengreen, Park y Shin (2011) postulan más bien una desaceleración del ritmo de crecimiento que obedece a la naturaleza de los avances previos y lo ejemplifica con dos casos clásicos: Japón y Corea del Sur. Al comparar el segundo con la RPC, estos autores subrayan cierto paralelismo. Corea es sinónimo de crecimiento acelerado, que -señalan- se inició en los sesenta con un tasa anual de expansión del PIB per cápita real de alrededor de 4.5\%; esa expansión se sostuvo por poco más de un cuarto de siglo, pero en la primera mitad de los noventa se apreciaron los primeros signos de desaceleración, que se neutralizaron sólo temporalmente elevando la formación de capital, que se acercó a 40\% del PIB. A la crisis de fines de los noventa, siguió una reestructuración que facilitó el tránsito a sectores de mayor contenido tecnológico, pero la tasa de crecimiento del PIB per cápita se ajustó a la baja en cerca de un tercio (Eichengreen, Park y Shin, 2011).

En el caso de la RPC habría ciertas reservas a la aplicación de una óptica similar a la usada para Corea del Sur, por la explicada coexistencia, ciertamente inestable, de dos mecanismos de asignación de recursos. Como se aprecia en la gráfica 2, el descenso del crecimiento del PIB en la RPC se verificó a partir de 2007, lo que sugiere que su principal causa fue la crisis financiera global, sin embargo, los signos de desaceleración se presentaron brevemente hacia 2003-2004 y se reflejaron en un pequeño descenso de la tasa de crecimiento de la productividad total de los factores y de la rentabilidad empresarial (Yueh, 2010).

La dirigencia china anunció oficialmente la política de rebalance de la economía a fines de 2004 tras advertir el descenso del consumo y el aumento del 
Gráfica 2. PIB de la RPC. Variación porcentual anual

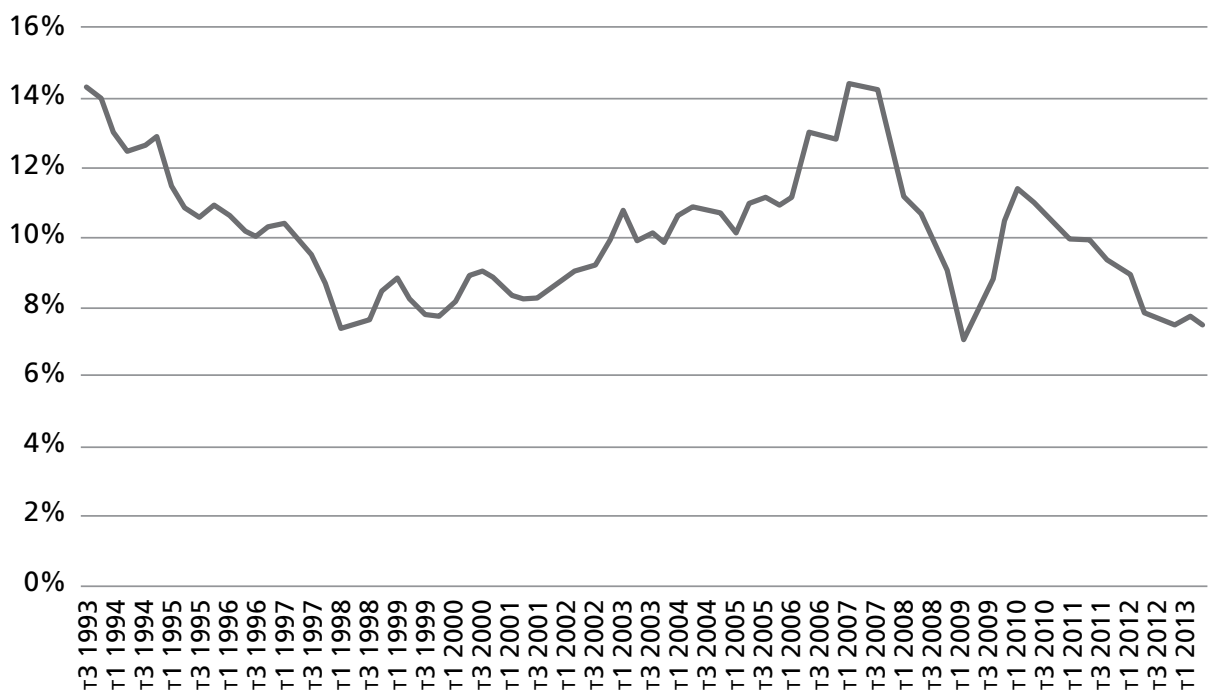

Fuente: Thomson Reuters Datastream.

ahorro y la inversión. El consumo, como porcentaje del PIB, pasó de casi $70 \%$ en los ochenta a $60 \%$ en los noventa, lo que constituyó el eje del "desbalance". La nueva estrategia consistía en pasar el motor del crecimiento a la demanda interna y a los servicios. Sin embargo, como se advierte en la gráfica 3, falló, ya que el consumo siguió disminuyendo en términos relativos y aumentando la inversión. Esta última se acercó a 50\% del PIB hacia 2008-2009. Además, desde 2010 el crecimiento del PIB bajó de nuevo.

Como respuesta a la desaceleración global, las autoridades elevaron la oferta monetaria; el incremento del dinero en circulación, en su definición más amplia, se elevó a 40\% del PIB en 2009 y a 30\% en 2010. Los bancos recibieron la orden, literalmente, de prestar, lo cual acataron en la medida en que son, en realidad, entidades del Estado. De este modo, el crédito, como porcentaje del PIB, pasó de 120\% en 2008 a 169\% en 2012 (Dumas y Choyleva, 2011, p. 97). Uno de los efectos de la nueva estrategia fue la reducción acelerada del superávit en cuenta corriente. De representar 10\% del PIB en 2007, se redujo a $2.8 \%$ en 2011 (Yueh, 2013). Obviamente influyó en la reducción del superávit la menor demanda externa provocada por la desaceleración del crecimiento global, pero, sobre todo, ha sido decisivo el aumento de la inversión con fines no enteramente destinados a aumentar las exportaciones (urbanización, infraestructura para las ciuda- 
des del interior, etcétera). ${ }^{18}$ Ese aumento de la inversión, que se llamará aquí de compensación, es clave, porque ha representado un medio de absorber el exceso de ahorro, tratando de mantener un rápido crecimiento de la economía, uno de los pilares del pacto social implícito de la modernización de la RPC. Cabe subrayar que el impacto de esa inversión en la expansión económica es limitado debido a que sus rendimientos son menores.

Gráfica 3. Consumo, inversión y exportaciones netas de la RPC como porcentaje del PIB

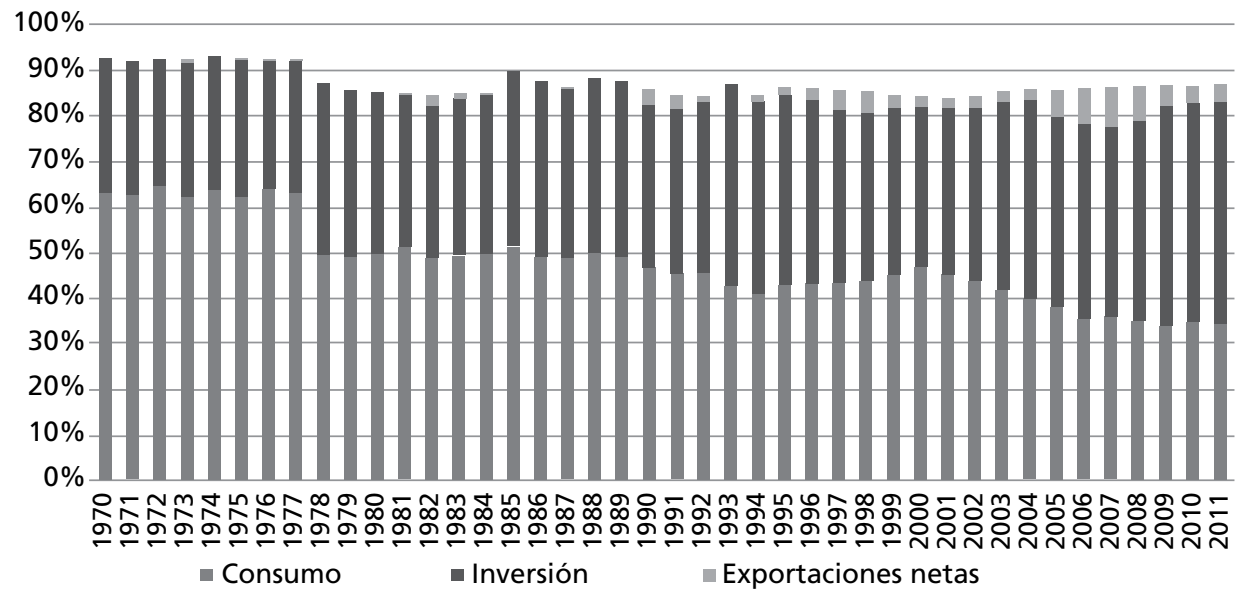

Fuente: Elaboración propia con datos de Banco Mundial (World Data Outlook).

Un resultado colateral previsible, si se tiene en cuenta el caso de Japón, fue la transformación de la inversión inmobiliaria en una burbuja especulativa (Barsky, 2011). El primer paso en ese camino fueron los gigantescos proyectos habitacionales emprendidos por el gobierno en pequeños pueblos, destinados a mejorar el nivel de vida de la población. El mecanismo inmobiliario ha sido básicamente el siguiente: los gobiernos municipales expropian grandes extensiones de tierra rural para llevar a cabo los grandes proyectos inmobiliarios. La tierra se vende a los desarrolladores; los ingresos recibidos se remiten a un vehículo financiero gubernamental no regulado (banco-sombra). Una función complementaria, pero crítica, de dicho vehículo es usar la tierra de modo colateral para obtener préstamos bancarios adicionales; los ingresos por esas dos vías se utili-

\footnotetext{
${ }^{18}$ Después de más de tres décadas de crecimiento acelerado, la economía china está ahogada en sobreproducción, desde acero hasta etileno.
} 
zan para pagar las compensaciones a los pobladores rurales y financiar los proyectos de infraestructura urbana. El mecanismo se va extendiendo progresivamente, provocando plétora inmobiliaria, debilitando a los bancos y empujando a la insolvencia de los vehículos financieros gubernamentales, con la consiguiente paralización de las obras urbanas. En la gráfica 4 se advierte el acelerado crecimiento de los préstamos otorgados por los bancos-sombra.

\section{Gráfica 4. Total de préstamos otorgados en la RPC como porcentaje del PIB}

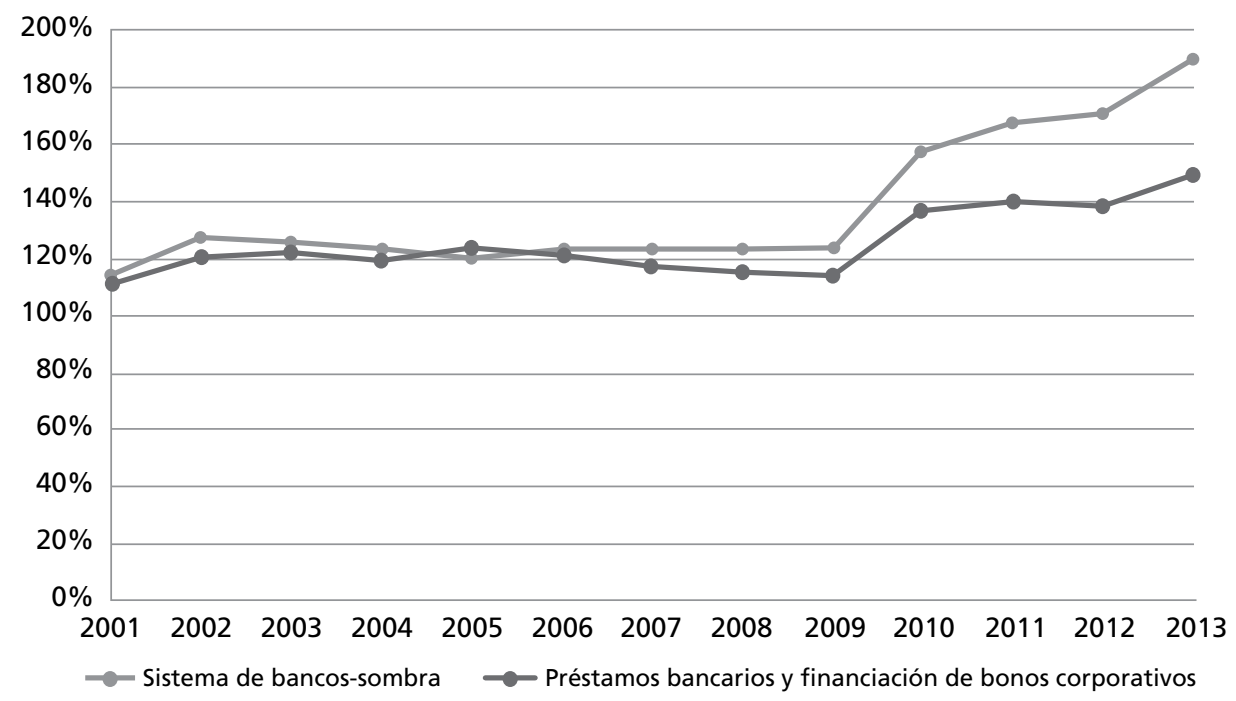

Fuente: Fondo Monetario Internacional.

Paralelamente, la plétora en la industria exportadora dificulta las condiciones de pago y pone en peligro, sobre todo, a las pequeñas empresas proveedoras, con menor poder de negociación. Las familias se ven igualmente arrastradas a la euforia crediticia, aumentando el riesgo de insolvencia.

Lardy (2012, p. 144 y ss.) alega que los principales generadores del desbalance son: a) la represión de las tasas de interés, b) la sobrevaluación cambiaria y c) las transferencias a favor de las EPE (crédito y subsidio en adquisición de insumos). De acuerdo con dicho autor, la liberalización completa provocaría un ajuste de mercado, eliminando los desequilibrios (sobreendeudamiento, exceso de exportaciones y dispendio de las EPE). ${ }^{19}$ Aunque esas medidas ayudarían a

\footnotetext{
${ }^{19}$ Lardy (2012, p. 151) es pesimista respecto a que se logre la liberalización, pese a los reiterados anuncios de los directores del Banco del Pueblo. Su argumento, ciertamente sugerente, es que
} 
restablecer cierto equilibrio macroeconómico, el problema de la RPC, al igual que el de Corea del Sur en los noventa, es esencialmente tecnológico.

La estrategia para promover las industrias de alta tecnología se anunció casi simultáneamente con las medidas a favor del rebalance, en 2004. El objetivo de "Los lineamientos para promover el desarrollo nacional de la industria de circuitos integrados", como se vio, es apuntalar la inversión masiva en educación superior, en investigación y desarrollo y en infraestructura para ciencia y tecnología, dándole una orientación específica hacia los circuitos integrados. Como se explicó, el eje geográfico es la ciudad de Pekín, seguida de Shanghái y Shenzhen-delta del río Perla. Aunque es deseable la estabilidad macroeconómica, la alineación de precios y el supuesto automatismo contribuirían escasamente a lograr el objetivo de acelerar el desarrollo del sistema de ciencia y tecnología. Lo que se requiere, como subraya Ernst (2014), es un nuevo tipo de intervención estatal más flexible y pragmática, que debe coexistir con la lógica mercantil-capitalista impuesta por la globalización; la necesidad de acatar esa lógica se acrecienta en tanto la economía china se acerca a la frontera tecnológica. En ese proceso, el modelo propuesto por Lardy (2012) resuelve el dilema a favor de la estabilidad macroeconómica, pero en contra de la independencia tecnológica.

\section{ConClusión}

La transformación ocurrida en la RPC es, en buena medida, parte del proceso más amplio verificado en Asia Nororiental; de allí provinieron no sólo el modelo estratégico y abundantes recursos financieros, sino, lo que es más importante, los canales de negociación con las potencias mundiales para facilitar el acceso a inversiones, mercados y, en una medida sustancial, a tecnología.

Para poner en marcha la reforma, se requirió reintegrar las estructuras de poder en torno a nuevos ejes que fueran compatibles con el mundo globalizado, pero manteniendo el pacto social de la era maoísta, a su vez enmarcado en el intento por congelar, por así decir, la transformación capitalista en un estadio que se ha llamado aquí "orgánico", frenando la total liberalización de la gestión económica.

la reforma le dio una base territorial de poder a una parte de la coalición dominante o Selectorado. La base territorial de poder son las siete unidades administrativas costeras (Guangdong, Jiangsu, Shanghái, Pekín, Zhejiang, Shandong y Fujian), que pugnan por mantener un régimen cambiario favorable a las exportaciones. 
Para preservar la estabilidad social y, a la vez, avanzar en la reforma, se adoptó una estrategia gradualista, experimental y flexible, subordinada en sus decisiones centrales al consenso del grupo dirigente, unos quinientos individuos, que ocupan las más altas posiciones de los órganos de gobierno y de las instancias partidistas. Ese grupo se halla unificado en torno a los objetivos estratégicos, pero cabe la interrogante de si al paso de las generaciones se preservará tal unidad.

La superación del caos que se asocia de manera natural con una transformación tan profunda fue posible gracias al sistema preexistente de descentralización y a la amalgama entre el poder central (que preservó para sí las palancas fundamentales) y la formación de un nuevo eje territorial de poder radicado en la región costera, desde Pekín hasta el delta del río Perla, conectada a Hong Kong.

Para transformar el anacrónico sistema de empresas estatales, se requería elevar sustancialmente la productividad agrícola, lo que se logró sorprendentemente más por iniciativa popular que por los decretos oficiales. Una vez desencadenado el cambio, sólo había dos opciones: profundizar la reforma o detenerla. Triunfó la primera, posibilitando la liquidación de la casi totalidad de empresas estatales, mediante la reestructuración a profundidad de un poderoso grupo de poco más de cien gigantes que constituyen una de las más poderosas palancas del intervencionismo estatal.

Esto último eliminó una de las barreras más formidables a la reforma socialista y dejó el camino abierto a la modernización del sistema bancario-financiero. Paralelamente, con el enorme avance logrado por la fábrica global china, se puso en marcha el aprendizaje tecnológico acelerado, con enormes inversiones en el llamado capital humano.

Las decisiones adoptadas en los primeros años del siglo XXI parece que fueron motivadas por la evidencia de que las altas tasas de crecimiento económico previas eran insostenibles. Pasó, así, a primer plano de la discusión el llamado rebalance de la economía y la necesidad de planes más audaces de promoción tecnológica. También se perfiló una posición radical que demandaba la liberalización total de la gestión económica, principalmente del tipo de cambio y de las tasas de interés. Visto el proceso superficialmente, se diría que las medidas adoptadas son, en el mejor de los casos, cautelosas y hasta ambiguas, pero en realidad la estrategia de la dirigencia china, como ya se explicó, es más compleja y ambiciosa. Tiene muchos factores en contra que se derivan de la lógica liberalizadora asociada a la globalización, pero, a su vez, el sistema neoliberal-financista global parece estar atascado en tasas precarias de crecimiento, lo que podría exigir re- 
formas, lo que tiene similitud con lo que la dirigencia de la RPC trata de promover; de ser así, ese país podría encontrarse a la vanguardia de un cambio histórico.

\section{REFERENCIAS BIBLIOGRÁFICAS}

Acemoglu, Daron y Robinson, James (2014), Por qué fracasaron los países. Los origenes del poder la prosperidad y la pobreza, Madrid, Deusto.

Acemoglu, Daron; Johnson, Simon, y Robinson, James (2004), "Institutions as the Fundamental Cause of Long-Run Growth", NBER Working Paper 10481, Cambridge.

Amsden, Alice (1989), Asia's Next Giant: South Korea and Late Industrialization, Oxford, Oxford University Press.

- (2001), The Rise of the Rest. The Challenges to the West from Late-Industrializing Economies, Oxford, Oxford University Press.

Asian Development Bank (2011), Asia 2050, Manila, ADB.

Aslund, Anders (2007), How Capitalism Was Built. The Transformation of Central and Eastern Europe, Russia, and Central Asia, Cambridge, Cambridge University Press.

Bairoch, Paul (1972), Revolución industrial y subdesarrollo, México, Siglo xxI.

Barsky, Robert (2011), "The Japanese Asset Price Bubble: A Heterogeneous approach", en Koichi Hamada, Arnil Kashyap y David Veinstein (eds.), Japan Bubble, Deflation and Long-Term Stagnation, Cambridge, The мIт Press.

Breznitz, Dan, y Murphree, Michael (2011), Run of the Red Queen. Government, Innovation, Globalization, and Economic Growth in China, New Haven, Yale University Press.

Buckley, Patricia (1996), The Cambridge Illustrated History of China, Cambridge University Press.

Chin, Gregory (2010), China's Automotive Modernization. The Party-State and Multinational Corporations", Londres, Palgrave Macmillan.

Clover Charles (2014) "Chinese tech: Selling to the next billion", Financial Times, p. 34, primera sección, 11 de noviembre.

Dabat, Alejandro; Rivera, Miguel Ángel, y Sztulwark, Sebastian (2007), "Rentas económicas en el marco de la globalización: desarrollo y aprendizaje. Implicaciones para América Latina", Problemas del Desarrollo, 38 (151), pp. 11-36.

Dean, Judith; Lovely, Mary, y Mora, Jesse (2009), "Decomposing China-Japan-us trade: Vertical Specialization, Ownership, and Organization Form", Journal of Asian Economics, 20 (6), pp. 596-610.

Dedrick, Jason, y Kraemer, Kenneth (2008), "Redes de conocimiento global en el desa- 
rrollo de nuevos productos: la industria de las PC portátiles", en A. Dabat y J. J. Rodríguez (coords.), Globalización conocimiento y desarrollo. La nueva economía global del conocimiento, tomo I, México, UNAM/M. A. Porrúa.

Dumas, Charles, y Chomyleva, Diana (2011), The American Phoenix. And Why China and Europe Will Struggle After the Coming Slump, London, Profile Books.

Eichengreen, Barry; Park, Donghyun, y Shin, Kwanho (2011), "When fast Growing Economies Slow Down: International Evidence and Implications for the People Republic of China", NBER Working Paper 16919, Cambridge.

Ernst, Dietern (2010), "Innovación offshoring en Asia: causas de fondo de su ascenso e implicaciones de política”, en M. de los Ángeles Pozas, M. A. Rivera y A. Dabat (coords.), Redes globales de producción, rentas económicas y estrategias de desarrollo: la situación de América Latina, México, El Colegio de México.

- (2014), "From Catching up to Forging Ahead? China's Prospects in Semiconductors", documento de trabajo, Innovation and Economic Growth Series, noviembre, East-West Center,

Evans, Peters (1995), Embedded Autonomy. State and Industrial Transformation, Princeton, Princeton University Press.

Felipe, Jesús (2012), “Tracking the Middle-Income Trap: What is it, Who is in it and Why?, ADB Working Paper 306.

Fukuyama, Francis (1992), El fin de la historia y el último hombre, Madrid, Planeta.

Garnaut, John (2012), The Rise and Fall of the House of Bo. How a Murder Exposed the Cracks in China's Leadership, Londres, Penguin Books.

Gereffi, Gary; Humphrey, John; Kaplinsky, Raphael, y Sturgeon, Timothy J. (2001), “Introduction. Globalization, Value Chains and Development", Institute of Development Studies Bulletin, 32 (3), pp. 1-8.

Greaney, Theresa, y Li, Yao (2009) “Assessing Foreign Direct Investment Relationships Between China, Japan and The United States", Journal of Asian Economics, 20 (6), pp. 611-625.

Hall, Peter, y Soskice, David (2001), Varieties of Capitalism. The Institutional Foundations of Comparative Advantage, Oxford, Oxford University Press.

Harwit, Eric (2008), Chinas's Telecommunications Revolution, New York, Oxford University Press.

Hoff, Karla, y Stiglitz, Joseph (2004), "La teoría económica moderna y el desarrollo", en Gerard Meier y Joseph. Stiglitz (eds.), Fronteras de la economía del desarrollo. El futuro en perspectiva histórica, México, Banco Mundial/Alfaomega.

Jisheng, Yang (2012), Tombstone: The Great Chinese Famine. 1958-1962, Hong Kong, Cosmos Books. 
Knight, John, Deng, Queng, y Li, Shi (2011), “The Puzzle of Migrant Labour Shortage and the Rural Labour Surplus in China", China Economic Review, 22 (4), pp. 585-600.

Koopman, Robert; Wei, Shang-Jin, y Wang, Zhi (2008), "How Much of Chinese Exports are Really Made in China", NBER Working Paper 14109.

Kornai, János (2008), From Socialism to Capitalism, Budapest, Central European University Press.

Lardy, Nicholas (2012), Sustaining China's Economic Growth After the Global Financial Crisis, Washington, DC, Peterson Institute for International Economics.

Lieberthal, Kenneth (2004), Governing China: From Revolution Through Reform, New York, Norton.

Lipton, Michael (2009), Land reform in Developing Countries: Property Right and Property Wrongs, London, Routledge.

Little, Lan; Scitovsy, Tibor, y Scott, Maurice (1975), Industria y comercio en algunos países en desarrollo, México, Fondo de Cultura Económica.

Lovell, Julia (2011), The Opium War, New York, Picador.

Ma, Ke, y Li, Jun (2004), El comercio en China, Beijing, China Intercontinental Press.

Maddison, Angus (2007), Contour of the World Economy", 1-2030AD, Essays in MacroEconomic History, Oxford, Oxford University Press.

Meng, Xin (2014), "Rural-Urban Migration in China", en S. Fan, R. Kanbur, S. J. Wei y $\mathrm{X}$. Zhang (eds.), The Oxford Companion to the Economics of China, Oxford, Oxford University Press.

Mokyr, Joel (1993), La palanca de la riqueza, Madrid, Alianza Editorial.

Naughton, Barry (2007), The Chinese Economy: Transition and Growth, Cambridge, The MIT Press.

North, Douglass (1984), Estructura y cambio en la historia económica, Madrid, Alianza Universidad.

North, Douglass; Wallis, John, y Weingast, Barry (2009), Violence and Social Orders. A Conceptual Framework for Interpreting Recorded Human History, Cambridge, Cambridge University Press.

Park, Tae-Young (2012), "How a Latecomer Succeeded in a Complex Product System Industry: Three Case Studies in the Korean Telecommunication Systems", Industrial and Corporate Change, 22 (2), pp. 363-396.

Rivera, Miguel Ángel (2009), Desarrollo económico y cambio institucional. Una aproximación al estudio del atraso económico y el desarrollo tardio desde la perspectiva sistémica, México, unAm/Juan Pablos. 
114 ECONOMÍA: TEORÍA Y PRÁCTICA • Nueva Época, número 44, enero-junio 2016

Schell, Orville, y Delury, John (2013), Wealth and Power. China's Long March to the Twenty-First Century, London, Little, Brown Book Group.

Shirk, Susan (1993), The Political Logic of Economic Reform in China, Berkeley, University of California Press.

Studwell, Joe (2013), How Asia Works. Success and Failure in the World's Most Dynamic Region, London, Proflile Books.

Wade, Robert (1999), El mercado dirigido. La teoría económica y la función del gobierno en la industrialización del este de Asia, México, Fondo de Cultura Económica.

Walter, Carl, y Howie, Fraser (2011), Red Capitalism, Singapure, John Wiley and Sons.

Wedeman, Andrew (2003), From Mao to Market. Rent Seeking, Local Protectionism and Marketization in China, Cambridge, Cambridge University Press.

Yao, Yang, y Zhang, Ke (2010), "Has China Passed the Lewis Turning Point? A structural estimation based on provincial data", China Economic Review, 3 (2), pp. 155-162.

Yifu, Justin (2012), Demystifying the Chinese Economy, Cambridge, Cambridge University Press.

Yueh, Linda (2010), The Economy of China, Cheltenham, Edward Elgar.

- (2013), China's Growth. The Making of an Economic Superpower, Oxford, Oxford University Press.

Zongsheng, Chen (2014), “Chinese Residents' Rising Income Growth and Distribution Inequality”, en S. Fan, R. Kanbur, S. J. Wei y X. Zhang (eds.), The Oxford Companion to the Economics of China, Oxford, Oxford University Press. 